\title{
Platform for Promoting a Hydrogen Economy in Southwest Europe: the HYRREG Project
}

R. Fernandes, C. Gonzalo, J.M. García, E. Chacón

This document appeared in

Detlef Stolten, Thomas Grube (Eds.):

18th World Hydrogen Energy Conference 2010 - WHEC 2010

Parallel Sessions Book 5: Strategic Analyses / Safety Issues / Existing and Emerging Markets

Proceedings of the WHEC, May 16.-21. 2010, Essen

Schriften des Forschungszentrums Jülich / Energy \& Environment, Vol. 78-5

Institute of Energy Research - Fuel Cells (IEF-3)

Forschungszentrum Jülich $\mathrm{GmbH}$, Zentralbibliothek, Verlag, 2010

ISBN: 978-3-89336-655-2 


\section{Platform for Promoting a Hydrogen Economy in Southwest Europe: the HYRREG Project}

Rei Fernandes, Instituto Superior Técnico, Portugal

Carmen Gonzalo, Fundación para el Desarrollo de las Nuevas Tecnologías del

Hidrógeno en Aragón, Spain

Juan Manuel García, Universidad Rey Juan Carlos, Spain

Esther Chacón, Instituto Nacional de Técnica Aeroespacial, Spain

\section{Introduction}

The effective promotion of hydrogen technologies is best achieved when there is a strategy and a well defined accepted plan. In order to promote a hydrogen-based economy the HYRREG project, funded by the program of cooperation of the territorial area of Southwest Europe (SUDOE), is developing a platform to generate hydrogen-related projects and a roadmap to enhance regional competitiveness and development of industry in the fields of hydrogen and fuel cell technologies. The project focuses on SUDOE which is comprised of 30 regions and autonomous cities representing about $770120 \mathrm{~km}^{2}$ (18.2\% area of EU-27) and $61.3 \mathrm{~m}$ inhabitants (12.4\% of EU-27).

The idea of a specific roadmap for SUDOE had its origin in "HyWays," a project undertaken by research institutes and industry, funded by the European Commission [1]. Although France and Spain were analysed in the HyWays project, regional stakeholders participating in HyWays saw the need for a more specific and thorough analysis focussing on the actual conditions by regions in SUDOE. The HyFrance project has already produced a roadmap for France and Portugal too has made progress towards a national roadmap through the HiPo project $[2,3]$. It is anticipated that the implementation of hydrogen technologies will contribute towards diversification and technical adaptation involving a large number of industries and SMEs, affording opportunities to develop new innovative products and services.

Much of the emphasis to date has been on the improvement of hydrogen technologies, but little has been done to transfer existing knowledge and expertise to SMEs and to build interregional networks of cooperation. The HYRREG project therefore established as its main objectives, (i) the establishment of a platform for the promotion of R\&D in cooperation with companies and for generating projects related to hydrogen, (ii) the development of a regional hydrogen roadmap for SUDOE and (iii) the dissemination of the project findings. These measures were designed to increase collaboration between the offices of technology transfer and other agents at both national and international levels and to raise awareness in society of the benefits of using such technologies.

\section{Characteristics of SUDOE}

Portugal and Spain have some of the highest energy dependencies in Europe, surpassed only by Italy, Ireland, Cyprus, Luxembourg and Malta in the European Union. In 2007 the levels of dependency were $82.0 \%$ and $79.5 \%$ respectively whereas that for France was 
50.4\%. Eurostat data for the year 2007 indicate that fossil fuels (hard coal, lignite, oil and gas) account for $80 \%$ and $84 \%$ respectively of the gross inland consumption of energy for Portugal and Spain [4]. In France the equivalent figure is $53 \%$ because of the large share of nuclear energy (42\%).

Renewable energy sources are growing steadily as sustainable policies to reach the EU 2020-20 targets are being implemented. Whilst the installed capacity for electricity generation from renewables in EU-27 grew 54\% in the decade to 2007, 58\% of that capacity was concentrated in just four countries (Germany, Spain, France and Italy). The increase was mainly due to wind capacity and SUDOE accounts for over 35\% of that capacity with contributions from Spain (16,740MW), France (3,404MW) and Portugal (2,862MW). HYRREG therefore believes that there is a good basis for supporting the development and introduction of hydrogen-based technologies in the region especially with respect to the use of hydrogen for storage. For Portugal and Spain the development of renewable energy is particularly important as both countries can be considered as "energy-deficient islands" due to their high energy dependency.

\section{The HYRREG Platform}

The purpose of the HYRREG platform therefore is to consolidate hydrogen-related activities in the region in order to promote cooperation between research institutes and industry. The approach is somewhat similar to that of the Hydrogen and Fuel Cell Technology Platform and the development of a strategic research agenda, a deployment strategy and an implementation plan, but also includes a proactive strategy of engagement. Links have been established with several institutions providing different support mechanisms within SUDOE. Agreements of cooperation have been signed with $\mathrm{AeH} 2$ (the Spanish Hydrogen Association with a membership of 36 enterprises, 17 research centres and 84 individual members) and the Spanish International Innovation Unit (UII) of Energy. Other institutions that are being approached include APPICE (the Spanish Association for Fuel Cells with 25 companies and 56 individual members), AP2H2 (the Portuguese Hydrogen Association with 17 companies), UII of $\mathrm{CO}_{2}$, PTE-HPC (the Spanish Platform of Hydrogen and Fuel cells comprised of 49 companies, 87 research, public and private entities), Aragonese Net of 7th Framework Programme, Agencia Andaluza de la Energía and the regional governments of Aragon, Castilla la Mancha and Comunidad de Madrid, An agreement has also been signed with PAC-H2. All these collaborators appear on the HYRREG website as "Collaborator Entities". Cooperation with regional governments offers a means of rapid implementation of hydrogen technologies initially as a bottom-up approach to disseminate and develop activities at local, regional and then national level but always with a vision for national strategies for hydrogen technologies.

HYRREG has been successful in launching a total of twenty five projects of which eleven are national, five European, three interregional (FR-ES) and two with Iberoamerica. The institutions involved will appear in a HYRREG catalogue containing details of stakeholders [5]. The collaboration with these entities is bidirectional as common objectives are followed, namely; sustainable development by means of renewable energies and/or hydrogen technologies. An online database of technologies and product opportunities in the field of 
hydrogen is being created for SUDOE and across Europe to help companies in the region to access international markets. The database allows one to search for new technology offers or requests and to find international partners. HYRREG has collaborated with the Spanish Hydrogen and Fuel Cells Platform, the Spanish Ministry of Science and Innovation instrument for promoting hydrogen technologies, in the National Plan for R\&D 2008-2011 to define strategic lines related to hydrogen technologies. The Portuguese Hydrogen Association is currently preparing a proposal to define the role of hydrogen in the national energy plan.

A catalogue listing profiles of companies or institutions working on hydrogen and fuel cells, their research lines and fields of interest, is currently under preparation as an aid to establishing links between the entities for the purpose of cooperation. The catalogue, which will be posted on the project website, will include technology transfer profiles highlighting technologies offered and those sought in the region. Other measures adopted to enhance cooperation between companies, universities and research institutes include a brokerage event at GENERA, the energy fair held in Madrid in May 2009 with more than 150 participants, of which $30-35 \%$ were directly related to hydrogen technologies. Presentations of the project have been made at HYCELTEC, an international conference held in Vila Real in Portugal, at special seminars held by $\mathrm{AeH} 2$ where there were about 100 attendees from the energy and research sectors and at the H2-Power Expo in Zaragoza.

\section{SUDOE Roadmap}

The SUDOE roadmap will focus on stakeholder preferences and country specific conditions such as availability of resources as well as the characteristics of the current and future energy systems in the region, applying a mainly qualitative analysis. The methodology consists of an iterative enquiry process of selected stakeholder groups involved in the energy sector. A questionnaire has already been launched and answers are in the process of being analysed. Following a SWOT analysis and a review of indicators selected by HYRREG, workshops will be held to produce a draft roadmap. Subsequently, after further analysis and the evaluation of hydrogen chains and deployment strategies a second version of a SUDOE roadmap will be produced.

\section{Opportunities and Challenges within SUDOE}

Whilst renewable energy technologies are quite well developed and already in common use, the intermittent nature of renewable sources means that they cannot be relied upon for base load. However the availability of an efficient means of storage coupled with energy management (balancing energy demand with energy supply) could significantly reduce the energy dependency in SUDOE. Hydrogen could provide a solution to the problem of energy storage. If renewable energies can be coupled to energy storage systems, they will become available to offset the growth in network capacity. Furthermore, they would become multipurpose, decentralized producers of electricity or hydrogen for fuel when the automotive industry enters mass production of hydrogen-fuelled vehicles. In the short term, marginal but significant benefits can be obtained by improving dispatch ability and offering reserve power and grid services. Other opportunities are being identified through a survey of more than 250 
stakeholders (150 Spanish, 70 Portuguese and 38 French). The responses indicate that hydrogen can be extremely valuable in SUDOE not only for energy storage when there is an excess, but also to supply remote areas and the islands in SUDOE with energy and as an alternative fuel for transport. These are the main end-use applications that hydrogen is envisaged to have in SUDOE.

\section{Technology Watch Reports}

Stakeholders in SUDOE have identified topics for "Technology Watch Reports" (TWR) that will summarize the state-of-the-art in a particular field providing extracts of relevant information on technology trends, developments, inventions, potential partners or competitors, emerging technological applications covering regulatory aspects and markets which can influence the success of a technological innovation. The preliminary list of 16 topics for the technology watch reports include mainly hydrogen production from renewables both with and without hydrolysis; from wind power through electrolysis; from high temperature solar energy using thermochemical cycles in combination with high temperature electrolysis; small scale reforming for refuelling stations; decarbonisation of methane and onboard production via chemical hydrides, reforming, ammonia and boranes. Other topics focus on PEM technologies (high temperature, alkaline PEM for electrolysis) and the stateof-the-art of SOFC. Two more topics for a state-of-the-art analysis are new batteries concepts vs. development and international normalisations and regulations concerning hydrogen storage and transport. Work has already begun and some topics are available on the website (www.hyrreg.eu). The report on small-scale reforming systems for hydrogen refuelling stations, for example, describes the different technologies and compares them, covering steam reforming, partial oxidation and autothermal technologies. It includes suppliers and takes into account market factors such as hydrogen production capacities, costs, fuel quality, size, load variation and star-up behaviour with some details of demonstration projects in different countries. Other reports cover patented technologies to assess their potential value by comparison with the market and by defining their strengths and weaknesses. In one case HYRREG estimated the value for licensing a patent and offered to help the research group negotiate the IP contract. These are just two examples of different technology watch report and their usefulness in technology transfer.

\section{Other HYRREG Activities}

The HYRREG project embraces some horizontal objectives including the training of technicians from Technology Transfer Offices (OTRIs) that are specialized in different specific sectors such as hydrogen technologies. Technicians from OTRI in Aragon have already gained some knowledge of hydrogen technologies through the new projects that have been launched. The level of action in terms of technologies involved has increased both within enterprises and in research centres. All the partners are necessarily in contact with companies and research centres for activities related to the work packages. Furthermore HYRREG plans awareness campaigns to highlight the advantages of using hydrogen technologies with a view to encouraging local authorities to start demonstration projects that are informative and that have a high social impact. 
To monitor progress, HYRREG has established a number of indicators based on the activities to be carried out by the partners of the consortium. All the tasks and actions have been enumerated and quantified to facilitate an assessment of progress.

\section{Conclusions}

Although the potential for hydrogen applications is virtually unlimited, transportation and early markets in portable applications are expected to be near-term drivers for a broader use of hydrogen, whilst stationary application related to wind energy and other renewables such as solar photovoltaics are promising. The inherent variable nature of wind and solar energy is limiting and poses problems of integration for market and grid operators. This may slow down their development in electricity markets where they already have a high penetration, but storage systems can provide a solution, allowing renewable energies to be closer to conventional energies. The HYRREG project grew from this scenario, based on two main activities, a platform to promote projects and a roadmap to define opportunities and strategies for the SUDOE region in new technologies in the energy, automotive, electronics and chemistry sectors. HYRREG is actively facilitating the implementation and use of sustainable technologies in agreement with European policies through interaction with the main regional stakeholders related to hydrogen technologies in industry, research centers, SMEs and Regional Governments by means of seminars, agreements, launching of projects, technology watch reports and brokerage events in a coordinated fashion to take advantage of market opportunities with innovative products and services.

\section{References}

[1] HyWays - Hydrogen Energy in Europe, Integrated Project under the 6th FP of the European Commission, 2004-2007, http://www.hyways.de

[2] Agator, J.M., and S. Avril, 2006. Towards a French Hydrogen Energy Roadmap: the HyFrance Project. WHEC 16 / 13-16 June 2006 - Lyon, France.

[3] Pimenta, R and Fernandes, T., 2008. Scenarios for the future of hydrogen in Portugal - the results of the Project HI-PO. WHEC 17 / 15-19 June 2008 - Brisbane, Australia.

[4] Energy, transport and environment indicators, 2009. Eurostat Pocketbook, 2009 edition. European Commission, Luxembourg.

[5] HYRREG Catalogue of Technology Profiles 2009 Edition, www.hyrreg.eu 